\title{
Paeoniflorin modulates multidrug resistance of a human gastric cancer cell line via the inhibition of NF-кB activation
}

\author{
SHENCUN FANG ${ }^{1 *}$, WEI ZHU ${ }^{2 *}$, YINGMING ZHANG ${ }^{1}$, YONGQIAN SHU ${ }^{2,3}$ and PING LIU ${ }^{2,3}$ \\ ${ }^{1}$ Ninth Department of Respiratory Medicine, Nanjing Chest Hospital, Nanjing 210029; \\ ${ }^{2}$ Department of Oncology, The First Affiliated Hospital of Nanjing Medical University, Nanjing 210029; \\ ${ }^{3}$ Cancer Center, Nanjing Medical University, Nanjing 210029, P.R. China
}

Received May 27, 2011; Accepted October 19, 2011

DOI: $10.3892 / \mathrm{mmr} .2011 .652$

\begin{abstract}
Research into the evasion of drug resistance and adverse effects is highly significant and urgent in the clinic. Therefore, accumulating studies have focused on the development of novel target-specific molecules related to drug resistance, and the establishment of rational therapeutic approaches. Currently, studies have shown that $\mathrm{NF}-\kappa \mathrm{B}$ activation may play an essential role in the development of chemotherapy resistance in carcinoma cells. Paeoniflorin, a principal bioactive component of the root of Paeonia lactiflora Pall., has been reported to exhibit various pharmacological effects. In the present study, we reported for the first time that paeoniflorin at non-toxic concentrations may effectively modulate multidrug resistance (MDR) of the human gastric cancer cell line SGC7901/vincristine (VCR) via the inhibition of $\mathrm{NF}-\kappa \mathrm{B}$ activation and, at least partly, by subsequently downregulating its target genes MDR1, BCL-XL and BCL-2.
\end{abstract}

\section{Introduction}

Multidrug resistance (MDR) constitutes a major obstacle to successful chemotherapy in cancer patients. In numerous cases, chemotherapies fail because of either intrinsic or acquired MDR of cancer cells following an initial round of treatment (1). Accumulating evidence indicates that there are three major mechanisms of drug resistance in cells: first, decreased uptake of water-soluble drugs including folate antagonists, nucleoside analogues and cisplatin (CDDP), which require transporters to enter cells; second, various changes in cells that affect the capacity of cytotoxic drugs to kill cells, also termed 'nonpump resistance', including alterations in the cell cycle, enhanced

Correspondence to: Dr Ping Liu, Department of Oncology, First Affiliated Hospital of Nanjing Medical University, 300 Guangzhou Road, Nanjing 210029, P.R. China

E-mail: liu-ping@csco.org.cn

*Contibuted equally

Key words: paeoniflorin, multidrug resistance, NF-кB, MDR1, BCL-XL, BCL-2
DNA repair activity, defective apoptosis pathway and altered metabolism of drugs, among others (2-4); third, increased energy-dependent efflux of hydrophobic drugs, also termed 'pump resistance', represented by overexpression of a family of energy-dependent transporters, known as ATP-binding cassette $(\mathrm{ABC})$ transporters, such as P-glycoprotein (Pgp, also known as ABCB1 or MDR1), MDR associated-protein 1 (MRP1, also known as ABCC1) and mitoxantrone resistance protein (ABCG2), among others (5).

The research on evading drug resistance and adverse effects is highly significant and urgent in the clinic. Therefore, previous studies have focused on developing novel target-specific molecules related to drug resistance and establishing rational therapeutic approaches. Currently, studies have shown that $\mathrm{NF}-\kappa \mathrm{B}$ activation may play an essential role in the development of chemotherapy resistance in carcinoma cells; evidence has also shown that $\mathrm{NF}-\kappa \mathrm{B}$ activation upregulates its target genes MDR1, BCL-XL and BCL-2, which are related to drug resistance of cancer cells (6-12). These findings led us to hypothesize that the nature of non-toxic NF- $\mathrm{NB}$ inhibitors, which also downregulate the expression level of MDR1, BCL-XL and BCL-2, may alter the MDR of cancer cells.

Paeoniflorin is a principal bioactive component of the root of Paeonia lactiflora Pall., a species of herb in found in China, Korea and Japan. It has numerous pharmacological effects including anti-inflammatory, anti-allergy, hepatoprotective and neuromuscular blocking, among others (13-17). Our previous investigation revealed that paeoniflorin inhibits $\mathrm{NF}-\kappa \mathrm{B}$ activation and enhances 5-fluorouracil (5-FU)-induced apoptosis in the human gastric carcinoma cell line, SGC790 (18). In the present study, we reported for the first time that paeoniflorin at non-toxic concentrations effectively modulates MDR of the human gastric cancer cell line SGC7901/vincristine (VCR) via the inhibition of NF- $\kappa \mathrm{B}$ activation and, at least in part, by subsequently downregulating its target genes MDR1, BCL-XL and BCL-2.

\section{Materials and methods}

Cell culture. Human gastric adenocarcinoma cell line, SGC7901 (obtained from the Academy of Military Medical Science, Beijing, China), and its multidrug-resistant variant, SGC7901/VCR (obtained from the State Key Laboratory of 
Cancer Biology and Institute of Digestive Diseases, Xijing Hospital, Fourth Military Medical University, Xian, China), were cultured in RPMI-1640 medium supplemented with $10 \%$ fetal calf serum (Gibco BRL, Grand Island, NY, USA) in a humidified atmosphere containing $5 \% \mathrm{CO}_{2}$ at $37^{\circ} \mathrm{C}$. To maintain the MDR phenotype, VCR (at a final concentration of $1 \mu \mathrm{g}$ / $\mathrm{ml}$ ) was added to the culture media for SGC7901/VCR cells.

In vitro drug sensitivity assay. The growth inhibitory effect of paeoniflorin on SGC7901/VCR cells was assessed using the MTT method. Paeoniflorin with a purity greater than 99\% was purchased from the National Institute for the Control of Pharmaceutical and Biological Products (batch no. 110736-200629, Jiangsu, China) and dissolved in RPMI-1640 medium.

SGC7901/VCR cells were seeded into 96-well plates $\left(5 \times 10^{3}\right.$ cells/well). Following cell adhesion, various concentrations of paeoniflorin $(0,20,40,80,160,320$ and $1000 \mu \mathrm{g} / \mathrm{ml})$ were added. A total of $48 \mathrm{~h}$ later, cell viability was assessed by MTT (Sigma, St. Louis, MO, USA) assay. The non-toxic concentration of paeoniflorin was estimated by the relative survival curve and further verified by the apoptosis assay.

To verify the MDR phenotype of the SGC7901/VCR cells, SGC7901 and SGC7901/VCR cells were seeded into 96-well plates $\left(5 \times 10^{3}\right.$ cells/well), as described previously (18), for the next step of the experiment, respectively. Following cellular adhesion, freshly prepared anticancer drugs, including VCR, 5-FU, CDDP, were added with the final concentration being 0.01-, 0.1-, 1- and 10-times the human peak plasma concentration for each drug, as previously described (19). The peak serum concentrations of various anticancer drugs are $0.5 \mu \mathrm{g} / \mathrm{ml}$ for VCR, $10 \mu \mathrm{g} / \mathrm{ml}$ for 5-FU and $2.0 \mu \mathrm{g} / \mathrm{ml}$ for CDDP $(20,21)$.

In addition, following the adhesion of SGC7901/VCR cells, anticancer drugs combined with paeoniflorin in a final concentration of $80 \mu \mathrm{g} / \mathrm{ml}$ or control RPMI-1640 medium without paeoniflorin, were added, respectively. A total of $48 \mathrm{~h}$ following addition of the drugs and paeoniflorin, cell viability was assessed by the MTT assay. The absorbance at $490 \mathrm{~nm}$ (A490) of each well was read on a spectrophotometer. The concentration at which each drug produced $50 \%$ inhibition of growth $\left(\mathrm{IC}_{50}\right)$ was estimated by the relative survival curve. Three independent experiments were performed in quadruplicate.

Apoptosis assay. To further assess the non-toxic concentration of paeoniflorin in SGC7901/VCR cells, SGC7901/VCR cells were seeded into 6 -well plates $\left(6 \times 10^{5}\right.$ cells/well $)$ and treated with various concentrations of paeoniflorin $(0,80$ and $160 \mu \mathrm{g} / \mathrm{ml}$ ) for $48 \mathrm{~h}$. Flow cytometry was used to detect the difference in apoptosis by determining the relative amount of AnnexinV-FITC-positive/PI-negative cells as described (19), respectively.

To affirm whether paeoniflorin at non-toxic concentrations sensitizes SGC7901/VCR cells to VCR-induced apoptosis, SGC7901/VCR cells in 6-well plates $\left(6 \times 10^{5}\right.$ cells/well) were treated with VCR at a final concentration of $5 \mu \mathrm{g} / \mathrm{ml}$, combined with paeoniflorin at a final concentration of $80 \mu \mathrm{g} / \mathrm{ml}$, or control RPMI-1640 medium without paeoniflorin, respectively. A total of $48 \mathrm{~h}$ following the treatment with VCR and paeoniflorin, the detection of cell apoptosis was also performed by flow cytometric analysis, as described previously (19).
$N F-\kappa B$ p 65 transcription factor assay. To determine NF- $\kappa \mathrm{B}$ activation, we performed an NF- $\kappa \mathrm{B}$ p65 transcription factor assay (Cayman Chemical Company, Ann Arbor, MI, USA), as previously described (18). This assay is a non-radioactive, sensitive method for detecting specific transcription factor DNA binding activity in nuclei. A 96-well enzyme-linked immunosorbent assay (ELISA) replaced the cumbersome radioactive electrophoretic mobility shift assay (EMSA). A specific double-stranded DNA (dsDNA) sequence containing the $\mathrm{NF}-\kappa \mathrm{B}$ response element was immobilized onto the bottom of the wells of the plate. A total of $48 \mathrm{~h}$ following the treatment of paeoniflorin at a final concentration of $80 \mu \mathrm{g} / \mathrm{ml}$ or the control RPMI-1640 medium, $50 \mu \mathrm{g}$ of nuclear proteins of the SGC7901/VCR cells was prepared, added to the wells and incubated overnight at $4^{\circ} \mathrm{C}$. NF- $\kappa \mathrm{B}$ binding specifically to the $\mathrm{NF}-\kappa \mathrm{B}$ response element was detected by the addition of specific primary antibodies directly against NF- $\mathrm{B}(\mathrm{p} 65)$. A secondary antibody conjugated to HRP was added and incubated for $1 \mathrm{~h}$ at room temperature to provide a sensitive colorimetric readout of $450 \mathrm{~nm}$. Human NF- $\mathrm{B}$ (p65) is able to be detected by this kit with no cross-reaction with $\mathrm{NF}-\kappa \mathrm{B}$ (p50).

Western blot analysis. SGC7901/VCR cells were seeded into 6 -well plates $\left(6 \times 10^{5}\right.$ cells/well) and treated with paeoniflorin at the final concentration of $80 \mu \mathrm{g} / \mathrm{ml}$. A total of $48 \mathrm{~h}$ following the treatment of paeoniflorin at a final concentration of $80 \mu \mathrm{g} / \mathrm{ml}$, or the control RPMI-1640 medium without paeoniflorin, nuclear and cytoplasmic extracts were prepared from the SGC-7901/ VCR cells. Nuclear and cytoplasmic proteins were separated by denaturing 12 and 10\% SDS-polyacrylamide gel electrophoresis, respectively. Western blot analysis was performed as described (19). The primary antibodies for p65 and histone H3 were purchased from Cell Signaling Technology (Danvers, MA, USA). The primary antibodies for MDR1, BCL-XL, BCL-2, Bax, $\alpha$-tubulin and GAPDH were purchased from Santa Cruz Biotechnology (Santa Cruz, CA, USA). Nuclear and cytoplasmic proteins were normalized to histone $\mathrm{H} 3, \alpha$-tubulin and GAPDH, respectively. Fold changes were determined.

Detection of the membrane expression level of MDRI by flow cytometry. SGC7901/VCR cells were seeded into 6-well plates ( $1 \times 10^{6}$ cells/well). On the following day, SGC7901/VCR cells were treated with paeoniflorin at a final concentration of $80 \mu \mathrm{g} / \mathrm{ml}$ or control RPMI-1640 medium without paeoniflorin, respectively. A total of $48 \mathrm{~h}$ following the treatment, cells were washed gently three times with cold phosphate-buffered saline (PBS) and collected by trypsin digestion and centrifugation. The cells were then fixed with $75 \%$ ethanol overnight. The following morning, cells were washed another three times with cold PBS and labeled using the MDR1-specific antibody (Abcam, Cambridge, UK) for $30 \mathrm{~min}$ at room temperature. Flow cytometry (FACSCalibur, BD Biosciences, NJ, USA) was then used to detect the membrane expression level of MDR1, as previously described (22). Data acquisition and analysis were performed on 10,000 cells using the Cell Quest software (BD Biosciences).

Rhodamine 123 (Rh123) accumulation and efflux assay. Accumulation and efflux of Rh123, determined by flow 
cytometry, was used as a functional index of MDR1 activity, as previously described (22). Cells were seeded into 6-well plates $\left(1 \times 10^{6}\right.$ cells/well $)$ and then treated with paeoniflorin at a final concentration of $80 \mu \mathrm{g} / \mathrm{ml}$, or control RPMI-1640 medium without paeoniflorin, respectively. A total of $48 \mathrm{~h}$ later, the medium was replaced by $2 \mathrm{ml}$ of medium containing Rh123 at a final concentration of $1 \mu \mathrm{g} / \mathrm{ml}$. Following incubation at $37^{\circ} \mathrm{C}$ for $2 \mathrm{~h}$, cells were washed twice with ice-cold PBS and then collected for the detection of the green fluorescence of Rh123 by flow cytometry. To determine the efflux of Rh123, cells were incubated with $2 \mathrm{ml}$ of medium containing Rh123 at a final concentration of $1 \mu \mathrm{g} / \mathrm{ml}$ for $2 \mathrm{~h}$, the medium was then replaced by Rh123-free medium for another $2 \mathrm{~h}$ and cells were collected for detection of the green fluorescence of Rh123 by flow cytometry as described above.

Statistical analysis. Each experiment was repeated at least 3 times. Numerical data were presented as the mean \pm SD. The difference between means was analyzed using the Student's t-test. All statistical analyses were performed using SPSS11.0 software (Chicago, IL, USA). Differences were considered to be statistically significant at a p-value $<0.01$.

\section{Results}

Effect of paeoniflorin on cell viability. Treatment of SGC7901/ VCR cells with paeoniflorin resulted in dose-dependent cytotoxicity (Fig. 1). A significant decrease in cell viability was noted in the cells treated with paeoniflorin at $160 \mu \mathrm{g} / \mathrm{ml}$ for $48 \mathrm{~h}$. Paeoniflorin at concentrations equal to or less than $80 \mu \mathrm{g} / \mathrm{ml}$ was not significantly cytotoxic to SGC7901/VCR cells. The concentration of paeoniflorin leading to $50 \%$ inhibition in cell viability $\left(\mathrm{IC}_{50}\right)$ was approximately $324 \mu \mathrm{g} / \mathrm{ml}$.

An apoptosis assay by flow cytometry further verified that there was no significant difference in cell apoptosis when treated with paeoniflorin at the concentration of $80 \mu \mathrm{g} / \mathrm{ml}$, compared with the cells treated without paeoniflorin (data not shown).

Paeoniflorin modulates MDR of SGC7901/VCR cells. An in vitro drug sensitivity assay verified the MDR phenotype of the SGC7901/VCR cells compared with the parental SGC7901 cell line (data not shown). Furthermore, paeoniflorin at the non-toxic concentration of $80 \mu \mathrm{g} / \mathrm{ml}$, significantly altered the $\mathrm{IC}_{50}$ of SGC7901/VCR cells to VCR, 5-FU and CDDP, compared with the cells treated with control RPMI-1640 medium without paeoniflorin. The $\mathrm{IC}_{50}$ value of SGC7901/ VCR cells treated with paeoniflorin to VCR, 5-FU and CDDP was $8.07,11.2$ and $4.12 \mu \mathrm{g} / \mathrm{ml}$, respectively, while the $\mathrm{IC}_{50}$ value of the cells treated with the control RPMI-1640 medium without paeoniflorin to these anticancer drugs was 32.8, 33.6 and $7.01 \mu \mathrm{g} / \mathrm{ml}$, respectively (Fig. 2).

Paeoniflorin sensitizes SGC7901/VCR cells to VCR-induced apoptosis. It is well known that the development of drug resistance in various cancer cells has been linked to a reduced susceptibility to drug-induced apoptosis. Since paeoniflorin at non-toxic concentrations was able to alter the $\mathrm{IC}_{50}$ of SGC7901/ VCR cells to anticancer drugs, we hypothesized that paeoniflorin may sensitize SGC7901/VCR cells to VCR-induced apoptosis at the non-toxic concentration.

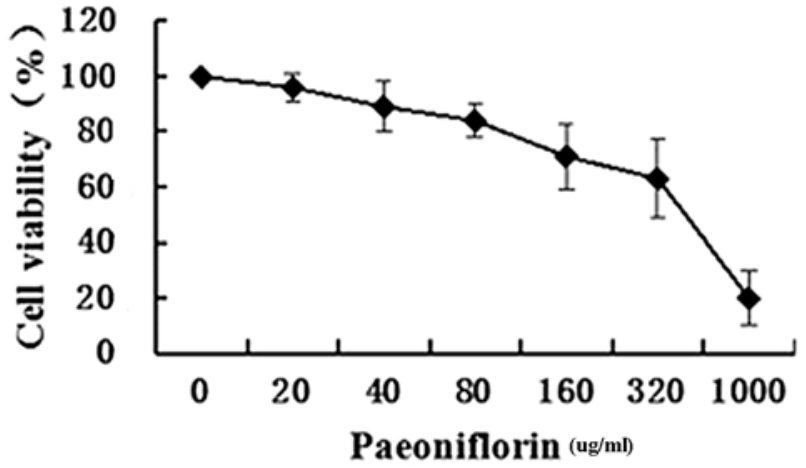

Figure 1. Effect of paeoniflorin on cell viability. Treatment of SGC7901/ VCR cells with paeoniflorin resulted in dose-dependent cytotoxicity, and a significant decrease in cell viability was observed in the cells treated with paeoniflorin at $160 \mu \mathrm{g} / \mathrm{ml}$ for $48 \mathrm{~h}$. Paeoniflorin at concentrations less than or equal to $80 \mu \mathrm{g} / \mathrm{ml}$ was not significantly cytotoxic to SGC7901/VCR cells. The concentration of paeoniflorin leading to $50 \%$ inhibition in cell viability $\left(\mathrm{IC}_{50}\right)$ was approximately $324 \mu \mathrm{g} / \mathrm{ml}$.

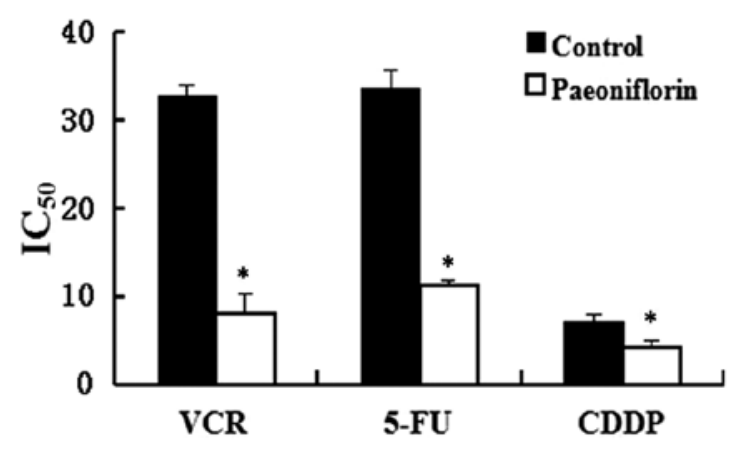

Figure 2. Paeoniflorin modulates multidrug resistance of SGC7901/VCR cells. Paeoniflorin, at the non-toxic concentration of $80 \mu \mathrm{g} / \mathrm{ml}$, significantly altered the $\mathrm{IC}_{50}$ values of SGC7901/VCR cells to VCR, 5-FU and CDDP, compared with the $\mathrm{IC}_{50}$ values of cells treated with the control RPMI-1640 medium without paeoniflorin to these anticancer drugs. The $\mathrm{IC}_{50}$ value of the SGC7901/VCR cells treated with paeoniflorin to VCR, 5-FU and CDDP was $8.07,11.2$ and $4.12 \mu \mathrm{g} / \mathrm{ml}$, respectively, while the $\mathrm{IC}_{50}$ value of the cells treated with the control RPMI-1640 medium without paeoniflorin-treated cells to these drugs was $32.8,33.6$ and $7.01 \mu \mathrm{g} / \mathrm{ml}$, respectively. ${ }^{*} \mathrm{p}<0.01$. VCR, vincristine; 5-FU, 5-fluorouracil; CDDP, cisplatin.

Indeed, cells treated with paeoniflorin at the non-toxic concentration displayed a significant increase in VCR-induced apoptosis, compared with cells treated with the control RPMI1640 medium without paeoniflorin (Fig. 3).

Paeoniflorin suppresses $N F-\kappa B$ activation. In our previous study we found that paeoniflorin was capable of suppressing $\mathrm{NF}-\kappa \mathrm{B}$ activation at least in part via the inhibition of $\mathrm{I} \kappa \mathrm{B} \alpha$ phosphorylation and degradation in parental SGC7901 cells (18). In this study, we investigated the expression and activation of NF- $\kappa \mathrm{B}$ in paeoniflorin-treated SGC7901/VCR cells.

The expression of the p65 subunit of $\mathrm{NF}-\kappa \mathrm{B}$ decreased significantly when cells were treated with paeoniflorin at $80 \mu \mathrm{g} / \mathrm{ml}$, compared with cells treated by the control RPMI1640 medium without paeoniflorin for $48 \mathrm{~h}$ (Fig. 4A). 

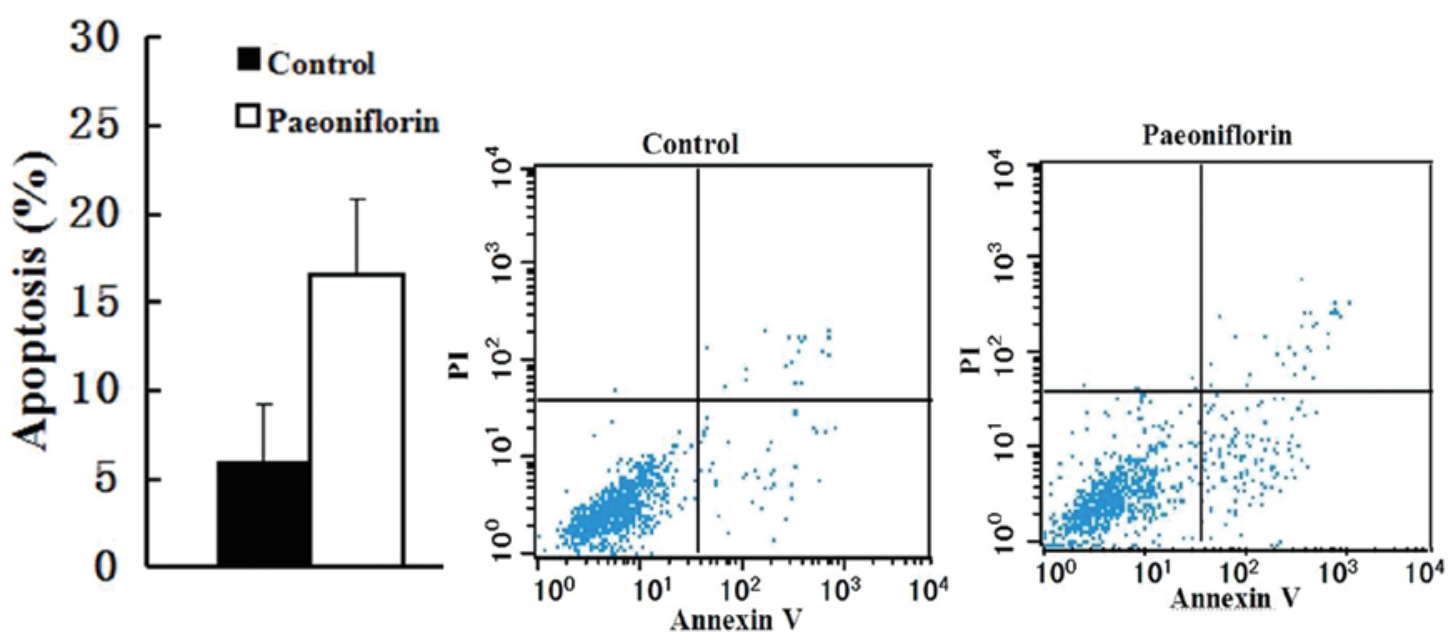

Figure 3. Paeoniflorin sensitizes SGC7901/VCR cells to VCR-induced apoptosis. Cells treated with paeoniflorin at the non-toxic concentration showed a significant increase in VCR-induced apoptosis, compared with cells treated with the control RPMI-1640 medium without paeoniflorin. A representative flow cytometry report is provided beside the graphs. ${ }^{*} \mathrm{p}<0.01$. VCR, vincristine.
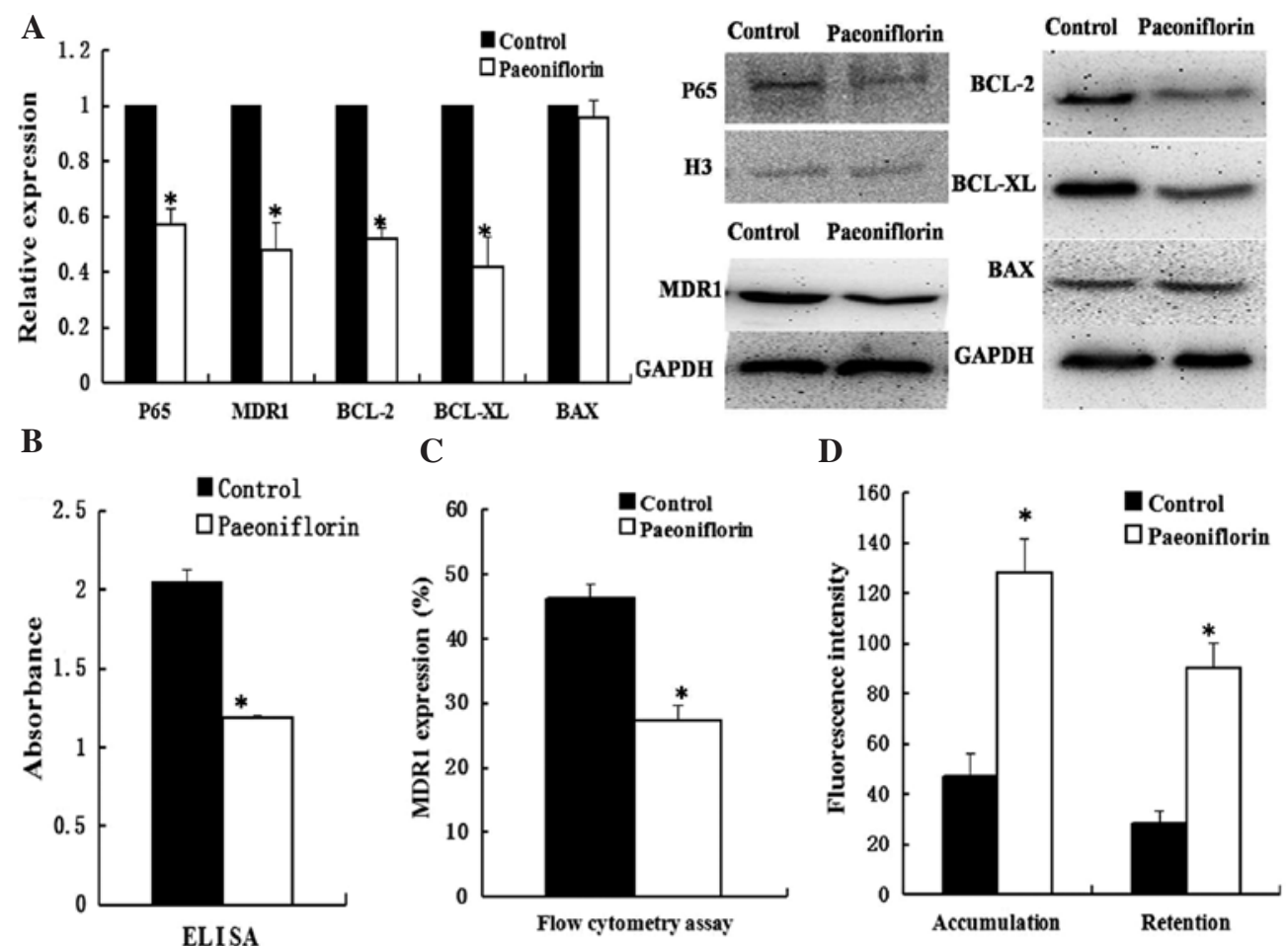

Figure 4. Paeoniflorin inhibits NF- $\mathrm{KB}$ activation and downregulates its target genes MDR1, BCL-XL and BCL-2. (A) Paeoniflorin at $80 \mu \mathrm{g} / \mathrm{ml}$ downregulates the expression levels of p65, MDR1, BCL-XL and BCL-2, but not Bax. Representative Western blot analysis is provided beside the graphs. (B) NF- $\mathrm{kB}$ p65 transcription factor assay (ELISA) revealed that paeoniflorin at $80 \mu \mathrm{g} / \mathrm{ml}$ inhibited intranuclear P65 transcription activation (1.188 \pm 0.01$)$, compared with treatment with the control RPMI-1640 medium without paeoniflorin $(2.053 \pm 0.07)$ for $48 \mathrm{~h}$. (C) Flow cytometry detection of the membrane protein MDR1 demonstrated that the expression level of MDR1 was significantly decreased in cells treated with paeoniflorin at $80 \mu \mathrm{g} / \mathrm{ml}$. A representative flow cytometry report is attached beside the graphs. (D) Rh123 accumulation and efflux assay demonstrated that the functions of MDR1 were significantly decreased in cells treated with paeoniflorin. "p<0.01. ELISA, enzyme-linked immunosorbent assay; Rh123, rhodamine 123; MDR, multidrug resistance.

To further analyze intranuclear NF- $\kappa \mathrm{B}$ transcription activity, NF- $\mathrm{B}$ p 65 transcription factor assay (ELISA) was performed. Similar to Western blot analysis, paeoniflorin at $80 \mu \mathrm{g} / \mathrm{ml}$ inhibited intranuclear p65 transcription activation (1.188 \pm 0.01$)$, compared with treatment with the control RPMI1640 medium without paeoniflorin $(2.053 \pm 0.07)$ for $48 \mathrm{~h}$ (Fig. 4B).
Paeoniflorin downregulates the expression level of MDR1, $B C L-X L$ and $B C L-2$. Since MDR1, BAX, BCL-XL and BCL-2 are direct target genes of NF- $\mathrm{KB}$, which are related to drug resistance of cancer cells, we hypothesized that paeoniflorin may modulate MDR of cancer cells via the inhibition of $\mathrm{NF}-\mathrm{\kappa B}$ activation and, at least in part, by subsequently downregulating its target genes MDR1, BCL-XL and BCL-2. 
Indeed, Western blot analysis revealed that the expression levels of MDR1, BCL-XL and BCL-2 were significantly downregulated in cells treated with paeoniflorin, with no significant changes in the expression of the pro-apoptotic protein BAX (Fig. 4A). Furthermore, flow cytometry detection of the membrane protein MDR1 and Rh123 accumulation and efflux assay further demonstrated that the expression level and function of MDR1 were significantly decreased in cells treated with paeoniflorin, respectively (Fig. 4C and D).

In conclusion, we suggest that paeoniflorin may modulate MDR of gastric cancer cells via the inhibition of NF- $\kappa \mathrm{B}$ activation and, at least in part, by subsequently downregulating its target genes MDR1, BCL-XL and BCL-2.

\section{Discussion}

The development of MDR of cancer cells remains a major limitation to successful chemotherapy in the clinic. The increased efflux of drugs and the defective apoptotic pathway are two major mechanisms of drug resistance in cancer cells, which are simply called 'pump resistance' and 'nonpump resistance'. In the present study, we found that paeoniflorin modulates MDR of gastric cancer cells via the inhibition of NF- $\kappa \mathrm{B}$ activation and, at least in part, by subsequently downregulating its target genes MDR1, BCL-XL and BCL-2, which play essential roles in the 'pump resistance' and 'nonpump resistance' of cancer cells, respectively.

$\mathrm{NF}-\kappa \mathrm{B}$, a ubiquitous transcription factor, is typically a heterodimeric complex composed of the Rel family proteins p50 and p65. It regulates various target genes that are able to interfere with apoptosis, cell cycle regulation, cell invasion and metastasis, as well as sensitivity of radiotherapy and chemotherapy (23). Emerging evidence suggests that constitutive activation of $\mathrm{NF}-\kappa \mathrm{B}$ has been observed and positively related to tumor progression in human gastric, and numerous other types of cancer (24-26). It has also been reported that NF- $\kappa B$ levels are significantly associated with poor prognosis of gastric cancer (27). Guo et al revealed that the activation of the $\mathrm{NF}-\kappa \mathrm{B}$ dimer was significantly higher in drug-resistant gastric cancer cell lines than its parental cell lines (28). Therefore, $N F-\kappa B$ is proposed as a specific molecule related to drug resistance and is a potential therapeutic target for the treatment strategy of gastric carcinoma. For instance, PDTC and MG132 (NF- $\kappa$ B inhibitors), are capable of inhibiting cell proliferation and reversing MDR in human gastric, and other types of cancer cells (29-31). It has also been reported that cyclosporin A is capable of enhancing taxotere-induced apoptosis in human gastric carcinoma cells, mainly via the inhibition of $\mathrm{NF}-\kappa \mathrm{B}$ activation (32). In agreement with these findings, our results revealed that paeoniflorin was capable of modulating MDR of gastric cancer cells and sensitizing cells to VCR-induced apoptosis via the inhibition of $\mathrm{NF}-\kappa \mathrm{B}$ activation.

What are the detailed molecular mechanisms involved in the reversal effect of paeoniflorin on drug resistance by inhibiting NF- $\kappa \mathrm{B}$ activation? In the present study, we analyzed the expression level of MDR1, BCL-XL and BCL-2 in paeoniflorin-treated cells, which are considered to be directly under the transcriptional control of NF- $\mathrm{KB}$.

Indeed, in our present study, we found that the expression level of MDR1 was significantly decreased in cells treated with paeoniflorin. Furthermore, paeoniflorin was capable of increasing intracellular Rh123 accumulation and decreasing the efflux of Rh123 in SGC7901/VCR cells, suggesting that paeoniflorin was capable of inhibiting the expression and function of MDR1 by suppressing NF- $\kappa$ B activation, therefore enhancing the sensitivity of cells to anticancer agents via modulating the 'pump resistance' mechanism.

Other than the modulation of the 'pump resistance' mechanism as described above, paeoniflorin was also capable of decreasing the expression level of anti-apoptotic BCL-XL and BCL-2, suggesting that paeoniflorin could modulate MDR via modulation of the 'nonpump resistance' mechanism.

It is well known that overexpression of BCL-2 in cancer cells is able to decrease the efficacy of ionizing radiation and chemotherapies (33). Kim et al reported that a number of chemotherapeutics were able to upregulate the expression level of anti-apoptotic proteins, such as BCL-2 and BCL-XL, and downregulate the expression level of pro-apoptotic protein Bax, via the NF- $\mathrm{B}$-dependent pathway, which provided a potential mechanism for the phenomenon of chemotherapy-induced chemoresistance (34). Therefore, reducing the expression level of anti-apoptotic proteins, such as BCL-2 and BCL-XL, may be a promising method of restoring the sensitivity of drug-resistant cancer cells to cytotoxic anticancer drugs $(35,36)$. Indeed, in the present study, the levels of BCL-2 and BCL-XL were downregulated by paeoniflorin via the inhibition of $N F-\kappa B$ activation, while Bax was not affected. Similar to our study, Morais et al found that inhibition of $N F-\kappa B$ activation by PDTC (an NF- $\kappa \mathrm{B}$ inhibitor) resulted in the decreased expression levels of BCL-2 and BCL-XL (31). Fahy et al also showed that the proteasome inhibitor bortezomib effectively inhibited $\mathrm{NF}-\kappa \mathrm{B}-$ mediated overexpression of BCL-2 and induced apoptosis in the majority of cancer cell types (37).

In conclusion, our study suggests that paeoniflorin is a potent and nontoxic therapeutic agent and may be used to modulate MDR of gastric cancer cells. Its role in the modulation of MDR may be mediated via the inhibition of $N F-\kappa B$ activity and, at least in part, by subsequently downregulating its target genes MDR1, BCL-XL and BCL-2. However, further studies are required to explore the effectiveness and safety of paeoniflorin in vivo, which may be helpful for developing a new strategy to overcome MDR of gastric cancer cells.

\section{Acknowledgements}

The authors are grateful to the funding support by the Bureau of Science and Technology of Jiangsu Province, P.R. China no. BS2007011.

\section{References}

1. Fan D, Zhang X, Chen X, Mou Z, Hu J, Zhou S, Ding J and Wu K: Bird's-eye view on gastric cancer research of the past 25 years. J Gastroenterol Hepatol 20: 360-365, 2005.

2. Rabik CA and Dolan ME: Molecular mechanisms of resistance and toxicity associated with platinating agents. Cancer Treat Rev 33: 9-23, 2007.

3. Johnstone RW, Ruefli AA and Lowe SW: Apoptosis: a link between cancer genetics and chemotherapy. Cell 108: 153-164, 2002.

4. Zhang K, Mack P and Wong KP: Glutathione-related mechanisms in cellular resistance to anticancer drugs. Int J Oncol 12: 871-882, 1998. 
5. Szakacs G, Paterson JK, Booth-Genthe C and Gottesman MM Targeting multidrug resistance in cancer. Nat Rev Drug Discov 5: 219-234, 2006.

6. Choi BH, Kim CG, Lim Y, Shin SY and Lee YH: Curcumin down-regulates the multidrug-resistance mdrlb gene by inhibiting the PI3K/Akt/NF kappa B pathway. Cancer Lett 259: 111-118, 2008.

7. Baud V and Karin M: Is NF- $\kappa \mathrm{B}$ a good target for cancer therapy? Hopes and pitfalls. Nat Rev Drug Discov 8: 33-40, 2009.

8. Bentires-Alj M, Barbu V, Fillet M, Chariot A, Relic B, Jacobs N, Gielen J, Merville MP and Bours V: NFkappaB transcription factor induces drug resistance through MDR1 expression in cancer cells. Oncogene 22: 90-97, 2003.

9. Chen C, Edelstein LC and Gélinas C: The Rel/NF-kappaB family directly activates expression of the apoptosis inhibitor Bcl-x(L) Mol Cell Biol 20: 2687-2695, 2000.

10. Pahl HL: Activators and target genes of Rel/NF-kappaB transcription factors. Oncogene 18: 6853-6866, 1999.

11. Barkett M and Gilmore TD: Control of apoptosis by Rel/ NF-kappaB transcription factors. Oncogene 18: 6910-6924, 1999

12. Catz SD and Johnson JL: Transcriptional regulation of bcl-2 by nuclear factor kappa B and its significance in prostate cancer. Oncogene 20: 7342-7351, 2001.

13. Kim ID and Ha BJ: Paeoniflorin protects RAW 264.7 macrophages from LPS-induced cytotoxicity and genotoxicity. Toxicol In Vitro 23: 1014-1019, 2009.

14. Lee B, Shin YW, Bae EA, Han SJ, Kim JS, Kang SS and Kim DH: Antiallergic effect of the root of Paeonia lactiflora and its constituents paeoniflorin and paeonol. Arch Pharm Res 31: 445-450, 2008

15. Liu DF, Wei W and Song LH: Protective effect of paeoniflorin on immunological liver injury induced by bacillus Calmette-Guerin plus lipopolysaccharide: modulation of tumour necrosis factor-alpha and interleukin-6 MRNA. Clin Exp Pharmacol Physiol 33: 332-339, 2006.

16. Zhong SZ, Ge QH and Li Q: Peoniflorin attentuates Abeta((142))-mediated neurotoxicity by regulating calcium homeostasis and ameliorating oxidative stress in hippocampus of rats. J Neurol Sci 280: 71-78, 2009.

17. Hung JY, Yang CJ, Tsai YM, Huang HW and Huang MS Antiproliferative activity of paeoniflorin is through cell cycle arrest and the Fas/Fas ligand-mediated apoptotic pathway in human non-small cell lung cancer A549 cells. Clin Exp Pharmacol Physiol 35: 141-147, 2008.

18. Wu H, Li W, Wang T, Shu Y and Liu P: Paeoniflorin suppresses NF-kappaB activation through modulation of I-kappaB alpha and enhances 5-fluorouracil-induced apoptosis in human gastric carcinoma cells. Biomed Pharmacother 62: 659-666, 2008.

19. Xia L, Zhang D, Du R, Pan Y, Zhao L, Sun S, Hong L, Liu J and Fan D: miR-15b and miR-16 modulate multidrug resistance by targeting BCL-2 in human gastric cancer cells. Int J Cancer 123: 372-379, 2008

20. Yamaue H, Tanimura H, Noguchi K, Hotta T, Tani M, Tsunoda T, Iwahashi M, Tamai $\mathbf{M}$ and Iwakura S: Chemosensitivity testing of fresh human gastric cancer with highly purified tumor cells using the MTT assay. Br J Cancer 66: 794-799, 1992.

21. Yamaue $H$, Tani M, Onishi $H$, Kinoshita $H$, Nakamori $M$, Yokoyama S, Iwahashi M and Uchiyama K: Locoregional chemotherapy for patients with pancreatic cancer intraarterial adjuvant chemotherapy after pancreatectomy with portal vein resection. Pancreas 25: 366-372, 2002.

22. Xia W, Zhao T, Lv J, Xu S, Shi J, Wang S, Han X and Sun Y: Celecoxib enhanced the sensitivity of cancer cells to anticancer drugs by inhibition of the expression of P-glycoprotein through a COX-2-independent manner. J Cell Biochem 108: 181-194, 2009.
23. Greten FR and Karin M: The IKK/NF-kappaB activation pathway - a target for prevention and treatment of cancer. Cancer Lett 206: 193-199, 2004

24. Sasaki N, Morisaki T, Hashizume K, Yao T, Tsuneyoshi M, Noshiro H, Nakamura K, Yamanaka T, Uchiyama A, Tanaka M and Katano M: Nuclear factor-kappaB p65 (RelA) transcription factor is constitutively activated in human gastric carcinoma tissue. Clin Cancer Res 7: 4136-4142, 2001.

25. Brown M, Cohen J, Arun P, Chen Z and Van Waes C: NF-kappaB in carcinoma therapy and prevention. Expert Opin Ther Targets 12: 1109-1122, 2008.

26. Li J, Jia H, Xie L, Wang X, Wang X, He H, Lin Y and Hu L: Association of constitutive nuclear factor-kappaB activation with aggressive aspects and poor prognosis in cervical cancer. Int J Gynecol Cancer 19: 1421-1426, 2009.

27. Levidou G, Korkolopoulou P, Nikiteas N, Tzanakis N, Thymara I, Saetta AA, Tsigris C, Rallis G, Vlasis K and Patsouris E: Expression of nuclear factor kappaB in human gastric carcinoma: relationship with I kappa $\beta \alpha$ and prognostic significance. Virchows Arch 450: 519-527, 2007.

28. Guo X, Ma N, Wang J, Bu X, Cheng Y, Sun K, Xiong H, Jiang G, Zhang $\mathrm{B}, \mathrm{Wu} \mathrm{M}$ and Wei L: Increased p38-MAPK is responsible for chemotherapy resistance in human gastric cancer cells. BMC Cancer 8: 375-383, 2008.

29. Zhang H, Wu JS and Peng F: Potent anticancer activity of pyrrolidine dithiocarbamate-copper complex against cisplatin-resistant neuroblastoma cells. Anticancer Drugs 19: 125-132, 2008

30. Zhang Y, Shi Y, Li X, Du R, Luo G, Xia L, Du W, Chen B, Zhai H, Wu K and Fan D: Proteasome inhibitor MG132 reverses multidrug resistance of gastric cancer through enhancing apoptosis and inhibiting P-gp. Cancer Biol Ther 7: 540-546, 2008.

31. Morais C, Gobe G, Johnson DW and Healy H: Inhibition of nuclear factor kappa B transcription activity drives a synergistic effect of pyrrolidine dithiocarbamate and cisplatin for treatment of renal cell carcinoma. Apoptosis 15: 412-425, 2010.

32. Nakahara C, Nakamura K, Yamanaka N, Baba E, Wada M, Matsunaga $\mathrm{H}$, Noshiro H, Tanaka M, Morisaki T and Katano M: Cyclosporin-A enhances docetaxel-induced apoptosis through inhibition of nuclear factor-kappaB activation in human gastric carcinoma cells. Clin Cancer Res 9: 5409-5416, 2003.

33. Reed JC: Bcl-2 family proteins. Oncogene 17: 3225-3236, 1998.

34. Kim SM, Lee SY, Yuk DY, Moon DC, Choi SS, Kim Y, Han SB, Oh KW and Hong JT: Inhibition of NF- $\kappa$ B by ginsenoside Rg3 enhances the susceptibility of colon cancer cells to docetaxel. Arch Pharm Res 32: 755-765, 2009.

35. Flaherty KT, Stevenson JP and O'Dwyer PJ: Antisense therapeutics: lessons from early clinical trials. Curr Opin Oncol 13: 499-505, 2001.

36. Klasa RJ, Gillum AM, Klem RE and Frankel SR: Oblimersen Bcl-2 antisense: facilitating apoptosis in anticancer treatment. Antisense Nucleic Acid Drug Dev 12: 193-213, 2002.

37. Fahy BN, Schlieman MG, Mortenson MM, Virudachalam S and Bold RJ: Targeting BCL-2 overexpression in various human malignancies Through NF- $\kappa \mathrm{B}$ inhibition by the proteasome inhibitor bortezomib. Cancer Chemother Pharmacol 56: 46-54, 2005. 